This report was prepared as an account of work sponsored by an agency of the United States Government. Neither the United States Government nor any agency thereof, nor any of their employees, makes any warranty, express or implied, or assumes any legal liability or responsibility for the accuracy, completeness, or usefulness of any information, apparatus, product, or process disclosed, or represents that its use would not infringe privately owned rights. Reference herein to any specific commercial product, process, or service by trade name, trademark, manufacturer, or otherwise does not necessarily constitute or imply its endorsement, recommendation, or favoring by the United States Government or any agency thereof. The views and opinions of authors expressed herein do not necessarily state or reflect those of the United States Government or any agency thereof.

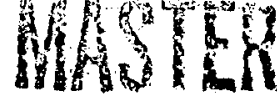

EGG-M- -05283

DE84 005031

\title{
REAL-TIME ULTRASONIC SENSING OF ARC WELDING PROCESSES
}

by

\author{
L. A. Lott, J. A. Johnson, \& H. B. Smartt \\ EG\&G Idaho, Inc. \\ Idaho Falls, Idaho
}

NDE techniques are being investigated for fusion zone sensing of arc welding processes tor closed-loop process control. An experimental study of pulse-echo ultrasonics fur sensing the depth of penetration of molten weld pools in structural metals during welding indicates that real-time ultrasonic sensing is feasible. Results on the detection of 1 iquid/solid weld pool interfaces, the determination of interface location, and effects of high temperature gradients uear the nolten zones on ultrasonic wave propagation are presented. Additional work required and problems associated with practical application of the techniques are discussed.

MODERN AUTOMATIC ARC WELDING equipment is very sophisticated, controlling the major machine functions such as welding current, arc voltage, travel speed, filler wire speed, mechanical motions of the torch, etc. Some machines are even microprocessor controlled. However, with few exceptions, information about the physical stale of the weld fusion zone is not used in real-time process control. (Exceptions to this are systems which use optical or IR sensors to measure the size or temperature of the Eusion zone surface on the opposite side from the torch of thin materials being welded.l) In almost all cases, the human operator "closes the loop" manually, adjusting the welding parameters during the process based on his observations. Thus weld quality is still strongly dependent on operator skill and experience for many automated arc welding applications.

Weld bead penetration is often critical. Unfortunately, the weld operator rarely is able to determine visually the extent of penetration. A sensing technique which can directly measure the extent of weld bead penetration (preferably from the

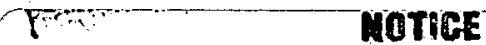

\section{PQRTIOHS OF THIS REPOAT ARE ULEGIBLE} ii has been reproduced from the best evallable copy to permit the broadest posslbie avallability. same side of the part as the welding torch) and provide real-time information Eor closed-loop control of the machine parameters to maintain the desired weld penetration configuration is a real need. In addition to the sensing technology, the implementation of such a system would require

- microprocessor control hardware (this is already available)

o a model of process parameter/bead geometry relationships ${ }^{2}$ (how must the welder parameters be changed to achieve a desired change in bead geometry)

- a process sensing algorithm (what must be done with the sensor signal to extract the desired penetration information)

o a process control algorithm (selection of the optimum parameters taking into account the process model, sensing, welding hardware and inherent process limitations).

Such an automatic welding machine is diagrammed in Fig. 1; the basic feedback loop consists of the molten weld pool, the process control sensor, the sensor data acquisition and signal processing system, the process controller, the welder power supply, the welding torch and arc, and back to the molten weld pool.

Ultrasonics shows promise for weld penetration sensing, as described in this paper. Ultrasonics has the potential to locate the edge of a molten weld zone by virtue of the unique ability of ultrasonic waves to propagate through thick metal structures and be reflected at 


\section{DISCLAIMER}

This report was prepared as an account of work sponsored by an agency of the United States Government. Neither the United States Government nor any agency Thereof, nor any of their employees, makes any warranty, express or implied, or assumes any legal liability or responsibility for the accuracy, completeness, or usefulness of any information, apparatus, product, or process disclosed, or represents that its use would not infringe privately owned rights. Reference herein to any specific commercial product, process, or service by trade name, trademark, manufacturer, or otherwise does not necessarily constitute or imply its endorsement, recommendation, or favoring by the United States Government or any agency thereof. The views and opinions of authors expressed herein do not necessarily state or reflect those of the United States Government or any agency thereof. 


\section{DISCLAIMER}

Portions of this document may be illegible in electronic image products. Images are produced from the best available original document. 


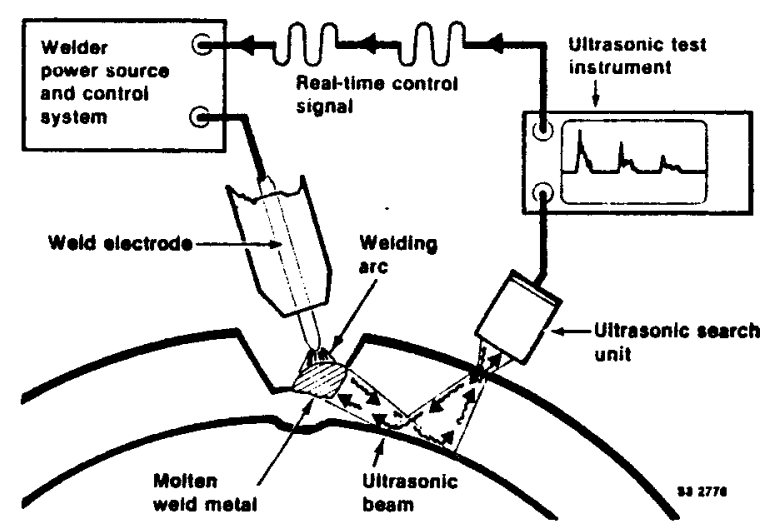

Fig. 1 - Uttrasonic controlled welding pricess concip

discontinuities in ultrasonic impedance such as accur at $1 \mathrm{iquid} / \mathrm{sol}$ id interfaces. By the detection and accurate timing of ultrasonic pulses retlected from the 1 iquid/solid intertace of a molten weld pool, the position of the interface could be determined and a process control signal generated to maintain the desired weld penetration. At liquid/solid interfaces of typical structural steels, the differences in density and longitudinal ultrasonic wave velocity between the liquid and solid phases are such that the amplitude reflection coefficients are approximately 0.1 , or $10 \% .3-7$ For ultrasunic shear waves, the theoretical reflection coefficient is 1.0 , or $100 \%$, since the 1 iquid stace will not support shear wave propagation.

\section{BACKGKOUND}

Ultrasonic techniques have been used to detect liquid/solid interfaces in a variety of different materials for applications including basic solidification studies, monicoring of crystal growth, and monitoring of metal casting processes. Bailey and Dula followed the motion of the liquid/solid interface during the freezing of water using $1.0 \mathrm{MHz}$ longitudinal ultrasonic waves incident from the liquid side. Bailey and Davila9, 10 also observed this intertace during the freezing of inercury and paraffin under unidirectional hetat flow comblions usiug $2.25 \mathrm{Mllz}$ longitudinal waves. Kurz and Lux 5-7 detected longitudinal wave reflection from $1 \mathrm{iquid} / \mathrm{sol}$ id interfaces in Wood's Metal, a

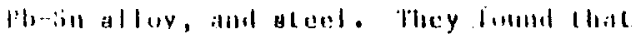
reflected ultrasonic signals were reduced by the geometry of the interface and by high atecumalion in loe solid material at high lemperatutes. At low solidificaliun rates during the casting of steel, they found that ruugh surfaces at the interface due to dendritic grain growth and the presence of a "mushy" transition zone between the solid and I iquid reduced the reflected ultrasonic signal. They also observed a decrease in sourd velocity in the solid of up to $25 \%$ caused by high temperatures which must be accounted for in thickness or interface location measurements. Lynnworth and Carnevale 4 observed both longitudinal and shear wave reflections at liquid/solid interfaces of steel in a study of continuous casting processes. They also observed that interface roughness due to dendritic grain growth reduced the reflected ultrasonic signal. They saw litcle advantage of shear waves despite the theoretical $100 \%$ reflectivity at the interface. Jeskey et al. 11 considered ultrasonic pulse-echo reflectivity measurements for monitoring steel ingot solidification. However, because of ultrasound propagation problems associated with coupling, high absorption, grain scattering, and ill-defined and irregular surtaces, a method based on through-transinission transit $t$ ime was used for solidification rate measurement. Parker ${ }^{3}$ studied the feasibility of pulse-echo ultrasonics for process control in continuous casting of metals. He succeeded in determining the position of the liquid/solid interface in $99.9 \mathrm{Sn}$ during both freezing and melting to $\pm 1 \mathrm{~mm}$ using $5 \mathrm{MHz}$ longitudinal ultrasound. Katzl 2 considered the possibility of ulerasonic measurement and control of weld penetration in a scudy similar to this work. He gave a guod analysis and discussion of the concept and reported some experimental results on molten zones at the ends of cylindrical rods. He failed to detect molcen weld pools in flat plate specimens but, nonetheless, concluded that ultrasonic weld pool dimensional measurement is potentially feasible.

The scope of the work described here is to study the problem of ultrasonically detecting, locating, and determining the dimensions of molten weld zones in structural steel. The main objectives are to determine the feasibility of the method and to obtain preliminary information needed as a first step toward developing an automatic closed-loop welding system controlled by ultrasonic sensors. The work is an experimental latoratory stuly in which stationary spot-on-plate welds are formed on the surface of steel specimens

simultaneously with ultrasonic monitoring of llie: witll anlle.

\section{EXPERIMENTAL METHODS}

The experimental measurements are performed with the test specimens suspended in a conventional ultrasonic imersion 
testing tank as shown schematically in Fig. 2. This is done in such a way chat the botcom surtace is immersed in water tu facilitace coupling of ultrasunic waves into the sample, while leaving the top surface dry for welding. The welder and corch are common gas tungsten arc welding (GTAW) equipment and are operated manually during experimental runs. The torch and ultrasonic transducer are mechanically connected so that after initial setup and alignment, the assembly. can be easily moved from point to point on the test specimen between test runs while maintaining alignment.

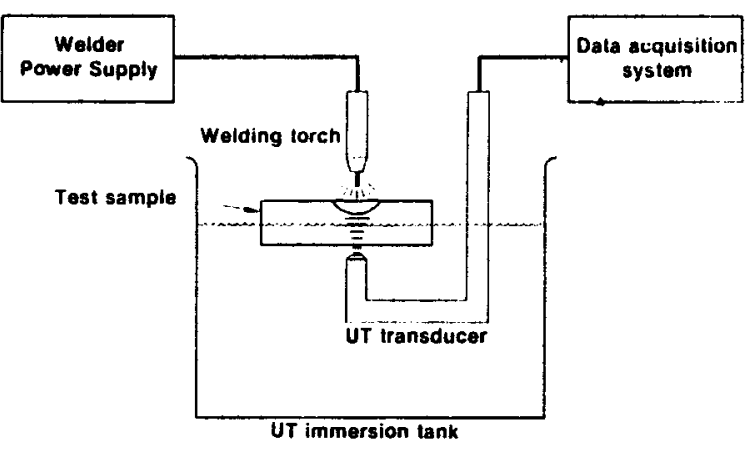

$\$ 2003$

Fig. 2 - Schematic diagram of experimental system

The test specimens are $25 \mathrm{~mm}$ ( 1 in.) thick by $100 \mathrm{~mm}$ ( $4 \mathrm{in.}$ ) wide by $360 \mathrm{~mm}$ ( 14 in.) long plates of carbon steel or 304 stainless steel. One specimen was prepared with a series of four evenly spaced holes $1.6 \mathrm{~mm}(0.063 \mathrm{in.})$ in diameter and approximately $25 \mathrm{~mm}$ ( 1 in.) deep drilled into the side of the specimen as shown in Fib. 3. When welding on the specimen directly above the holes and monitoring with ultrasunics from directly below as shown in Eig. 3, reflected ultrasonic signals from the weld pool region are received at the same time as reflections from the side drilled holes. In this way the side drilled hole reflections serve as internal markers of known position with which the position of the weld pool reflections can be calibraled. The data acquisition system is shown schematically in Fig. 4. Standard U.5-ill. diameter ultrasonic immersion transducers of nominal frequencies of $1,2.25,5$, and 10) Milz are used with a standardultrasonic

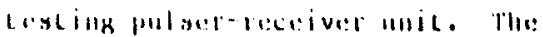
utrasonic Jata acquisition is completely automatic and computer controlled. The

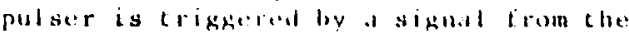
compuler and specificd portious of the received $A-s c a n s$ are digitized to 8 -bit accuracy at a maximum race of $20 \mathrm{MHz}$ by a

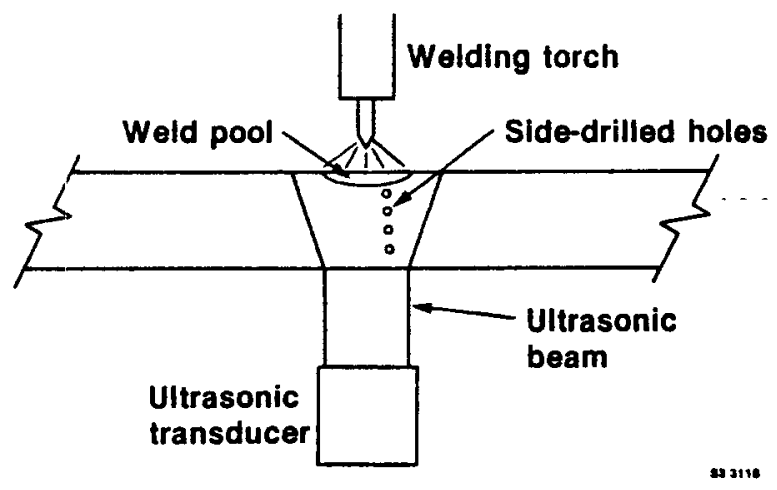

Fig. 3 - Test sample configuration

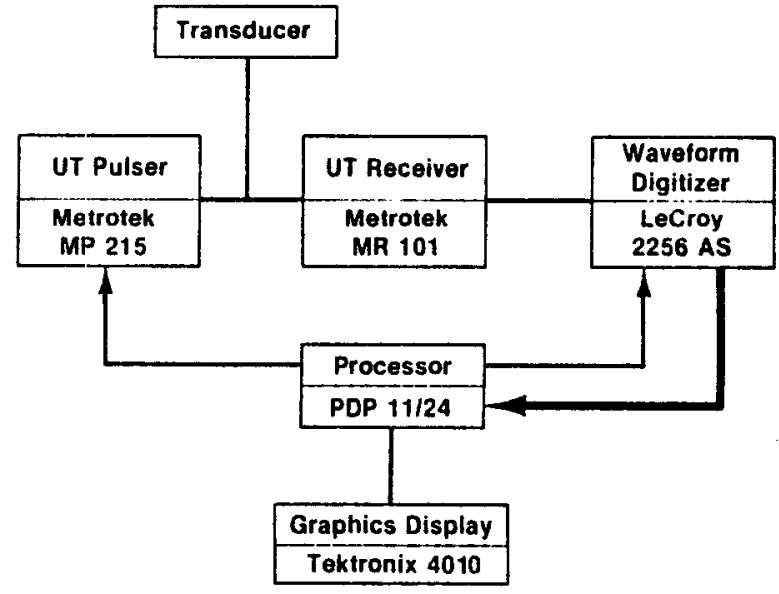

323805

Fig. 4 - Data acquisition system

waveform digitizer whose output is then stored in the computer. The data are stored on disk or magnetic tape and recalled at a later time for display and posttest processing. A purchased interactive data processing software package (ILS, signal Technology, Inc.) is used for data acquisition, file manipulation and management, processing, and display.

After initial setup and alignment of the welding corch, transducer, and sample, the computer is instructed to trigger the pulser at regular intervals and digitize and store windowed portions of the radio frequency A-scans. Typically, 20 or 30 A-scans are taken at $1-s$ intervals. Once the lata acyuldiliun cycle i initialed, the welder is turned on for a period of time, typically $10 \mathrm{~s}$, and then curned off. Thus,

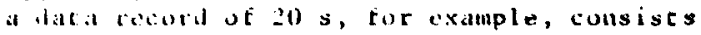
of unt or two A-scans showing the retlected signal from the top sample surface (no weld pool), then ten scans showing the reflected 
signal from the weld pool region as the pool forms and grows, and finally several more scans as the weld pool solidifies and cools.

\section{EXPERIMENTAL RESULTS}

In carbon steel and 304 stainless steel, reflected ultrasonic signals from at least two interfaces in the weld pool region are received for normally incident longitudinal waves. A typical result is shown in Fig. 5, a display of a computerized data record for a 16-s weld spor experiment on a stainless steel sample for $10 \mathrm{MHz}$ longitudinal waves. The $A$-scans were taken at $1-s$ intervals before, during, and after a molten weld spot was forned in the sample.

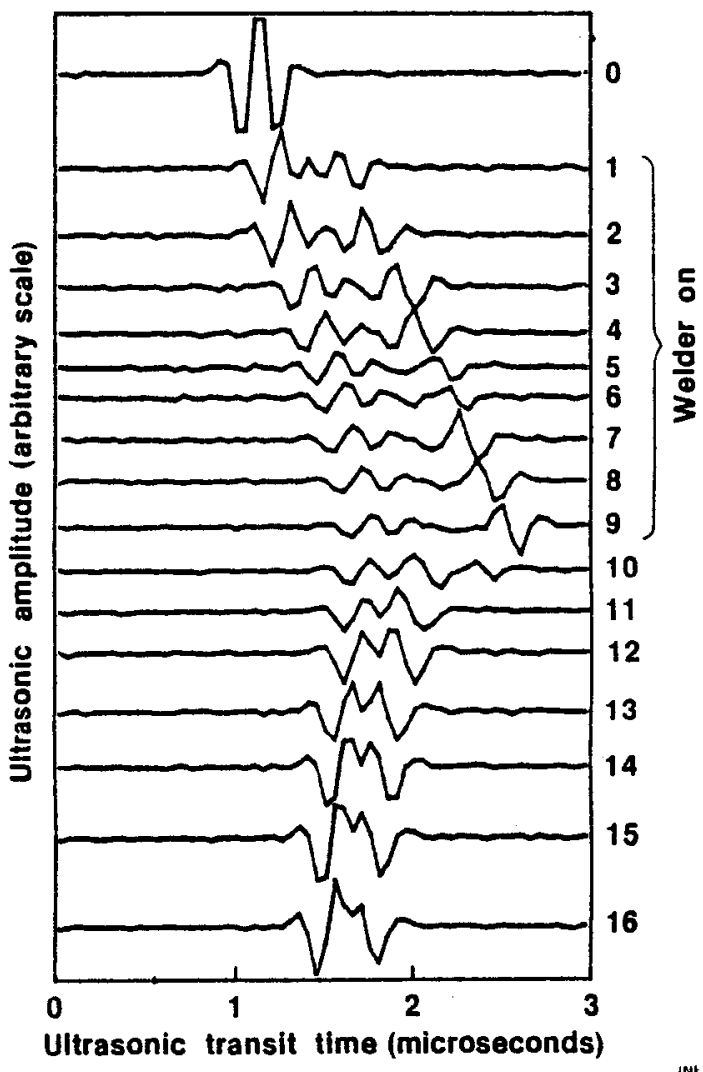

NEL : : $4: 43$

rig. 5 - Ultrasonic A-scans of weld spot in solit stuinlass stcul

The first scan (time zero) was obtained before clie welder was turned on and shows only the: rellection Irum Lhe upper sulid/ais surface of the sample. The next nine scans were lakell while che walder was on and a molten weld pool furmed and grew in size. As the pool started to form, the single reflected signal split into two reflected pulses which separated further in time as the pool grew in depth. After the welder was turned off, the two reflected pulses coalesced into a single signal as the pool solidified and cooled. The final reflected pulses are distorted because of the nonplanar surface of the weld spot and disturbance of the beam by the weld zone microstructure. Note also that in addition to separating in time during welding, both reflected pulses moved to the right

(Fig. 5), corresponding to longer time delays. This effect is caused by the high temperatures present in the sample;

ultrasonic wave velocities are known to decrease with increasing temperature, 5 thus producing the shift to longer time delays. This is discussed in more detail below under Analysis and Interpretation. The two reflected pulses from the molten weld pool are more easily distinguishable in Fig. 6 which shows two of the A-scans of Fig. 5 plotted in different time and amplitude scales. The first A-scan of Fig. 6, which is the first A-scan of Fig. 5, shows the reflected pulse from the top surface of the sample before the welder was turned on; the other A-scan is the tenth scan of Fig. 5, which was taken just before the welder was turned off when the weld pool was deepest. The two pulses are easily distinguishable in the later scan and the time interval between chem (approximately 1 us) can be measured. There is a noticeable difference in shape between the two pulses: the first being similar (however atcenuated) to the original solid/air reflected pulse, but the second distinctively different in both damping
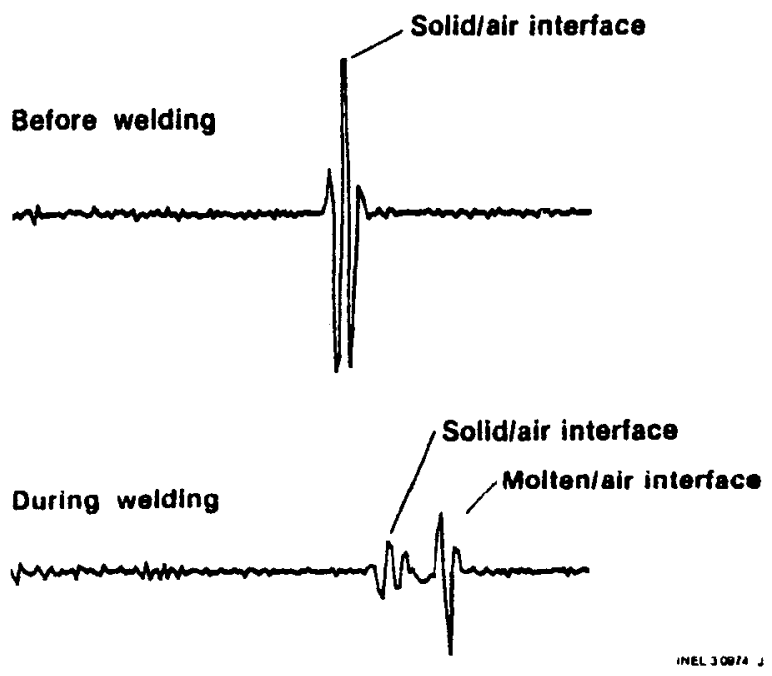

Fin. 6 - Selected ultrasonic A-scans of Fig. 2 at differenc amplicude and time scales (scans $\# 0$ and $\$ 9$ ) 
(number of peaks in the pulse) and phase (largest peak negative instead of positive). This implies that a pattern recognition technique based on these features might be successful in discriminating between the various signals received in an actual weld monitoring application, if necessary.

In the later scan of Fig. 6, an area of low level signal $c$ an be seen ahead in time of the two main reflecting pulses, indicating the presence of a third interface in the weld pool region. The interpretation of the ultrasonic data and the

identification of the three interfaces are discussed in the next section.

\section{ANALYSIS AND INTERPRETATION}

An understanding and incerpretation of the experimental data require calculation of the temperature gradients around the weld pool and of the effects of the gradients on the sound field. The gradients are calculated by numerically solving the heat flow equations. A numerical ray-tracing program is then used to determine the effects of the gradient.

TEMPERATURE GRADIEN'T CALCULATIONS - The thermal-hydraulics code STEALTH 13 is used to calculate the temperature gradients as a function of time. The problem is modeled by a fixed weld-pool boundary which is at the melting temperature of the steel. The heat flow from this boundary into the solid steel is calculated as a function of $t$ ime, and from this the temperature distribution in the solid steel is calculated.

The mesh used in this calculation is shown in Fig. 7. (Note: Figs. 7 and 8 are oriented upside down relative to all other figures.) The horizontal axis is the radial distance from the centerline of the weld pool and the vertical axis is the distance iroin the tup of the weld poul. The left boundary is the axis of symmetry for this axially symmetric model. The curved portion of the mesh boundary represents the 1 iquid/solid intertace which is at the melting temperature $\left(1400^{\circ} \mathrm{C}\right)$ of

304 stainless steel. The bottom horizontal boundary, which is actually adjacent to room temperature air in the experiment, is modeled as an adiabatic boundary. The remaining boundaries are in water at $20^{\circ} \mathrm{C}$ anil are isothurinal.

The STEALTH code requires that the material properties and the initial conditions of the mesh be input. The

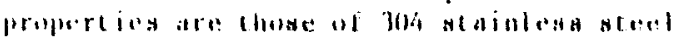
as given in keferences 14 and 15 and Table 1 . The entire solid steel volume is assumest to bes at 20 "c at the gtart of the piublell.

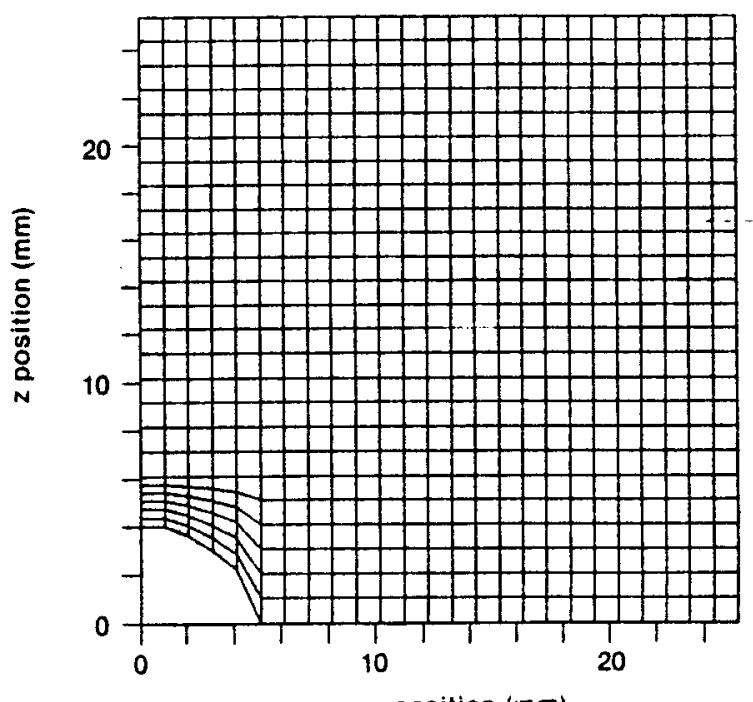

$x$ position $(\mathrm{mm})$

INEL 31477

Fig. 7 - Mesh used in numerical calculation of temperature distribution

$$
\begin{gathered}
\text { Table I - } 304 \text { Stainless Steel } \\
\text { Properties }
\end{gathered}
$$

Density

Solid

Liquid

$8.0 \mathrm{~g} / \mathrm{cm}^{3}$

$6.9 \mathrm{~g} / \mathrm{cm}^{3}$

Bulk Modulus

$1.63 \times 10^{12} \mathrm{dyne} / \mathrm{cm}^{2}$

Shear Modulus

$7.31 \times 10^{11}$ dyne $/ \mathrm{cm}^{2}$

Heat Capacity

$4.0 \times 10^{7} \mathrm{erg} / \mathrm{cm}^{3}{ }^{\circ} \mathrm{C}$

Thermal Conductivity $1.62 \times 10^{5} \mathrm{erg} / \mathrm{cm}^{\circ} \mathrm{C}$

Given the initial conditions, the code calculates the temperature at the center of each mesh quadrilateral and the heat flux through each edge of each quadrilateral. This information is recalculated at time intervals of $0.01 \mathrm{~s}$ using the information from the previous cycle.

The results of the calculation can be plotted or printed. Fig. 8 shows the $i$ sotherms around the weld pool at $5.0 \mathrm{~s}$ after the start of the problem. The five contour level.s correspond to $1100,900,700$, 500 , and $300^{\circ} \mathrm{C}$ moving away from the weld poul. The calculated temperacures ac the center of each mesh cell are then used as input to the ray-tracing program described next.

KAY TKAilNi; - The ray-tracing propram calculates the effects of the temperature distribution on the rays of the sound firlil. in fineral, two eftects atcur: Changes in the sound speed with temperature and the consequent refraction of the sound 


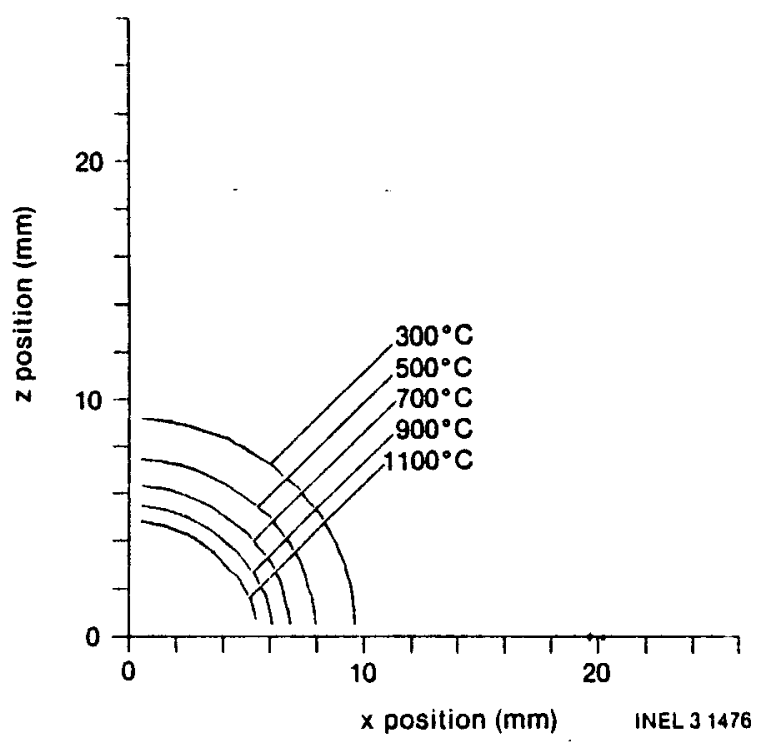

Fig. 8 - Isotherms around a $4 \mathrm{~mm}$ deep weld at $5.0 \mathrm{~s}$

beam due to the sound-speed changes. The first affects the timing of the returning echues and the second affects the apparent lateral position of the reflectors.

The sound tield is modeled by a point source of sound at the bottom surface of the part on the centerline of the beam of the actual transducer. Rays are traced from this point into the material at any angle, accounting for the variation of the sound speed due to the temperature distribution in the part.

The material is divided up into a large number of thin layers. Within each layer the sound is assumed to travel in a straight line at a speed determined by the temperature at the center of the layer on the line of the ray. The time for the ray to craverse the layer is then calculated from the sound speed, thickness, and ray direction.

The refraction of the rays at the boundary between layers is shown in Fig. 9. A linear least-squares $f$ it in two dimensions is inade to the temperature distribution using the four temperature values nearest the intersection of the ray and the layer bundary. These values are taken from the output of the STEALTH program as described above. The expression for the temperature astribution in the neighborhose of the: ray/boundary intersection is then

$$
T=a x+b y+c
$$

where $a, b$, and $c$ are the coefficients derived in the fitting process and $x$ and $y$ are the Cartesian courdinates. From this an

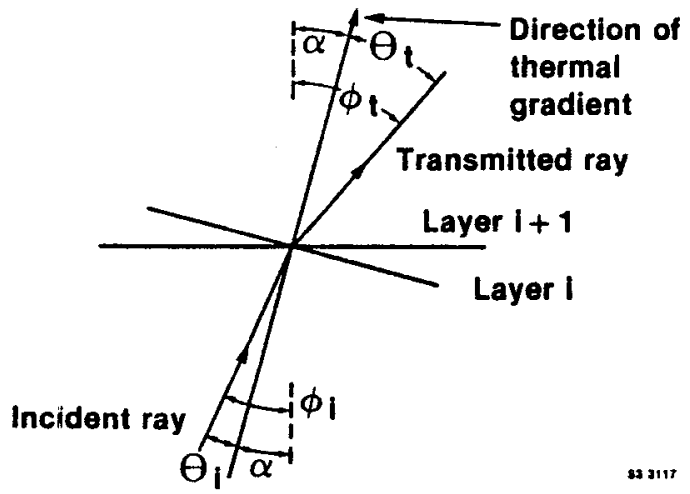

Fig. 9 - Refraction of a ray at a boundary between layers

expression for the gradient is found to be

$$
\vec{\nabla} T=a \hat{i}+b \hat{j}
$$

The angle of the temperature gradient relative to the axis is

$$
\alpha=\operatorname{Tan}^{-1} \frac{a}{b}
$$

The direction of the gradient is in the same direction as the normal to a plane surface, shown in Fig. 9. This plane surface is the boundary between the two regions of

different temperature in this numerical model. It is also then the dividing line between two regions with different sound speeds. Thus the incident and refracted angles used in Snell's law must be calculated relative to the normal to this plane or relative to the direction of the temperature gradient.

The incident ray is assumed to be at angle $\phi$ relative to the $y$ axis as shown in Fig. 9. The angle relative to the surface normal as required by Snell's law to calculate the refracted angle in the next layer is:

$$
\theta_{i}=\phi_{i}-\alpha
$$

Using Snell's law the refracted angle relative to the surface normal can be found

$$
\sin \theta_{t}-\frac{v_{t}}{v_{i}} \sin \theta_{i}
$$

whert $V_{i} i$ the sound speed in the incident layer and $v_{t}$ is the sound speed in the next layer. Finally the angle relative to the $y$ axis in the next layer is calaulated.

$$
\phi_{t}=\theta_{t}+\alpha
$$


The sound speeds are calculated from the temperature at the center of the layer along the 1 int of the incident ray using a straight-line fit to the measurements of Kurz and Lux for $\times 5$ CrNi $18 / 9$ steel. 5 These data are assumed to approximate that for 304 stainless steel.

For rays entering the liquid phase, the same procedure is followed except that the temperature is assumed to be constant in the weld pool. This temperature is chosen to be approximately the average temperature of the pool or $1900^{\circ} \mathrm{C}$. By extrapolating the data of Kurz and Lux ${ }^{5}$ to $1900^{\circ} \mathrm{C}$, the velocity in the 1 iquid is found to be $3.6 \mathrm{~mm} / \mathrm{s}$. The path of any ray entering the 1 iquid is extended $0.7 \mathrm{~mm}$ above the level surface of the part to account for the meniscurs formed above the pool due to the expansion of the steel upon melting.

The calculation starts by assuming a given position of the point source and of the initial ray angle. The ray is then traced through successive layers until it reaches the top surface of the steel block. The time for the ray to reach any point in the block may be determined and from that the round-trip time for an echo returning from that point calculated. The relative $t$ ime from different reflectors $c$ an then be determined and compared to experimental values.

RESULTS - Eig. 10 shows three rays traced through the steel. The center ray is directed normally co the surface of the part, travels to the weld pool (represented by the dotted 1 ine), into the pool, and finally to the top surface. The actual sound field would be partially reflected at the positions of the side-drilled holes, at the solid/liquid interface, and at the top surface. The other rays are at the smallest angle such that the rays will just $\mathrm{miss}$ the weld pool and intersect the top surface after traveling only chrough the solid. The interpretation of the observed echoes is based on the times for the rays to reach each incerface as calculated by the ray tracing program and are shown in Table 2. Fig. Il shows the interpretation

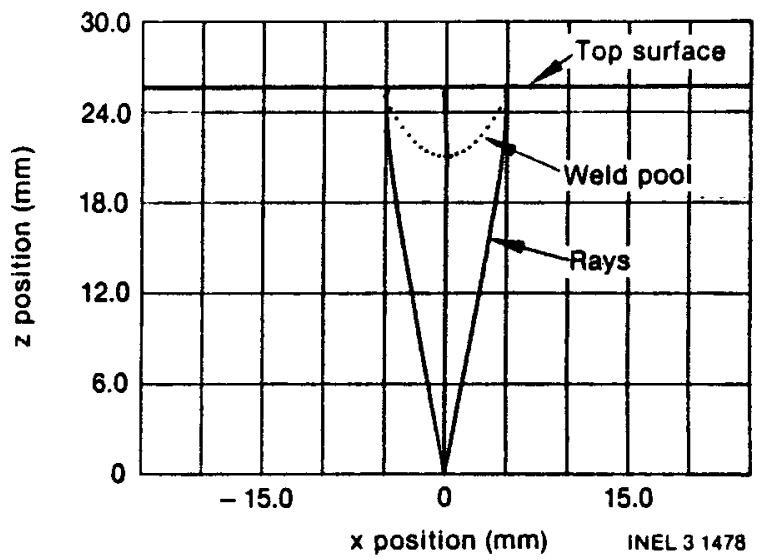

Fig. 10 - Three rays traced from the botcom of the part through and around the weld pool

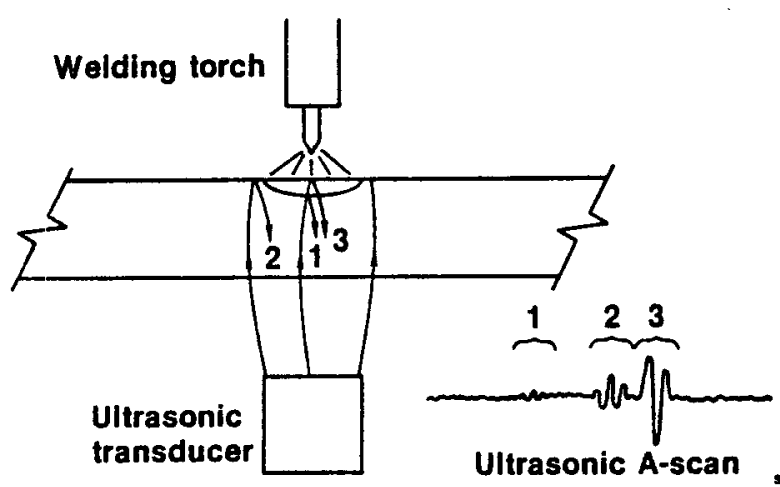

Fig. 11 - Interpretation of the three observed echoes

of the observed echoes. The $t$ imes of the echoes are calculated relative to the time for the echo from the side-drilled hole that is second from the top. These times are then compared to those observed in the experiment and the correlation that is shown in Table 2 is obtained.

Table 2 - Calculated and observed echo times ( $\mu s$ )

Interface

2nd side-drilled hole

lst side-drilled hole

Liquid/solid interface (1)

Solid/air interface (2)

Liquid/air incerface (3)

\begin{tabular}{cc}
$\begin{array}{c}\text { Relative } \\
\text { Time }\end{array}$ & $\begin{array}{c}\text { Observed } \\
\text { Relative } \\
\text { Time }\end{array}$ \\
\hline .0 & 0.0 \\
1.83 & 1.85 \\
2.42 & 2.60 \\
4.16 & 4.10 \\
5.04 & 4.75
\end{tabular}


Figure 12 shows two A-scans, one taken before the welder was turned on and one at 5 s after. The data from Table 2 are also plotted with the arrow marking the time for the second side-drilled hole aligned with the first positive peak of the echo from that interface. The other arrows can be seen to align closely with the corresponding echoes in the A scan.

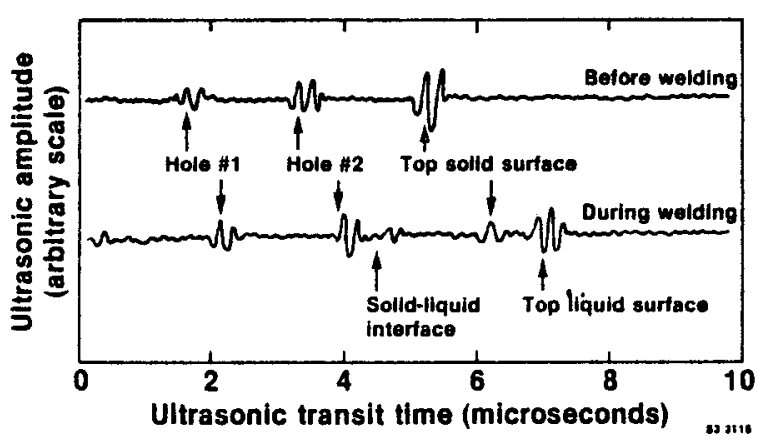

Fig. 12 - Comparison of calculated echo tines with A-scan

This interpretation is supported by two experimental observations. The last signal received, as seen on an oscilloscope screen during the experiment, was observed to fluctuate rapidly with time in a manner suggesting a signal reflected from a disturbed free liquid surface, which a molten weld pool surface certainly is. Unfortunately, the data acquisition system can take data only about every second and this dynamic action does not appear in the digitized A scans. The small echo due to the 1 iquid/solid interface was observed to move gradually earlier in time relative to the side-drilled hole, corresponding to the expected gradual increase in the depth of the pool.

These signals can be used to measure the weld-pool depth. Unfortunately, the signal from the 1 iquid/solid interface is small and is not always present. However. the $t$ ime difference between the other two echoes is approximately proportional to the pool depth. The time difference can be calculated relative to the time for the echo frum the solid/liquid interiace

$$
\begin{aligned}
& t_{3}=t_{1}+2 D / V_{x} \\
& t_{2}=t_{l}+2 D / V_{s}
\end{aligned}
$$

whete Lie subscripls reler lo lhe rays sluwll in Fig. 11 and $D$ is the pool depth.

However, the time chrough the pool must be modilied to account for the meniscus. for a pool depth of $4 \mathrm{~mm}$, the meniscus has been calculated to be $0.7 \mathrm{~mm}$ high. The path length throwgh the liquid is then increased in proportion to the pool depth and the time $t_{j}$ is recalculated:

$$
\begin{gathered}
\Delta D=\frac{0.7}{4} D \\
t_{3}=t_{1}+\frac{2(D+\Delta D)}{V}
\end{gathered}
$$

The time difference and the pool depth can be calculated.

$$
\begin{gathered}
t_{3}-t_{2}=2 D \frac{1.175 v_{s}-V_{\ell}}{v_{s} v_{\ell}} \\
D=\frac{v_{s} v_{\ell}}{2\left(1.175 v_{s}-v_{\ell}\right)} \Delta t
\end{gathered}
$$

$=3.95 \Delta t$

where the average value for the speed $V_{s}=5.0 \mathrm{~mm} / \mu \mathrm{s}$ around the pool is determined from the ray tracing program and the average value through the pool is the same as estimated above $\left(v_{Q}=3.6 \mathrm{~mm} / \mu \mathrm{s}\right)$. The results from three weld pools of different depths, made by using three different welder power inputs, are sumnarized in Fig. 13. The A-scans recorded just before the welder was turned off are shown along with a photomicrograph of the solidified fusion zone for each weld pool. (Note that it is much easier to identify the position of the reflected pulses when the complete series of A-scans can be seen and compared.) A plot of ultrasonic transit times versus weld pool depths for the data of Fig. 13 is shown in Fig. 14. The result is a linear plot wich a slope of 4.0 compared to 3.95 calculated above.

SUMMARY AND CONCLUSIONS

We have demonstrated that molten weld pools in structural steels can be detected ultrasonically and the data understood, both qualitatively and quantitatively, in terms of the weld pool configuration and the surrounding temperature gradients. Using longitudinal ultrasonic waves, information about weld pool depth, or penetration, for a simple weld configuration can be obtained during welding which might be used for clased-luip process control.

Befure practical application of the techniques on realistic welding processes, however, additional work needs to be done in several areas. The high temperature unviroment near a weld zone presents bot hardware and data interpretation problems. The hardware prublems are associated with lhe process of coupling ultrasonic energy into a hot test piece. These problems should be solvable by the use of cooled ultrasonic searih heads, momentary contact 

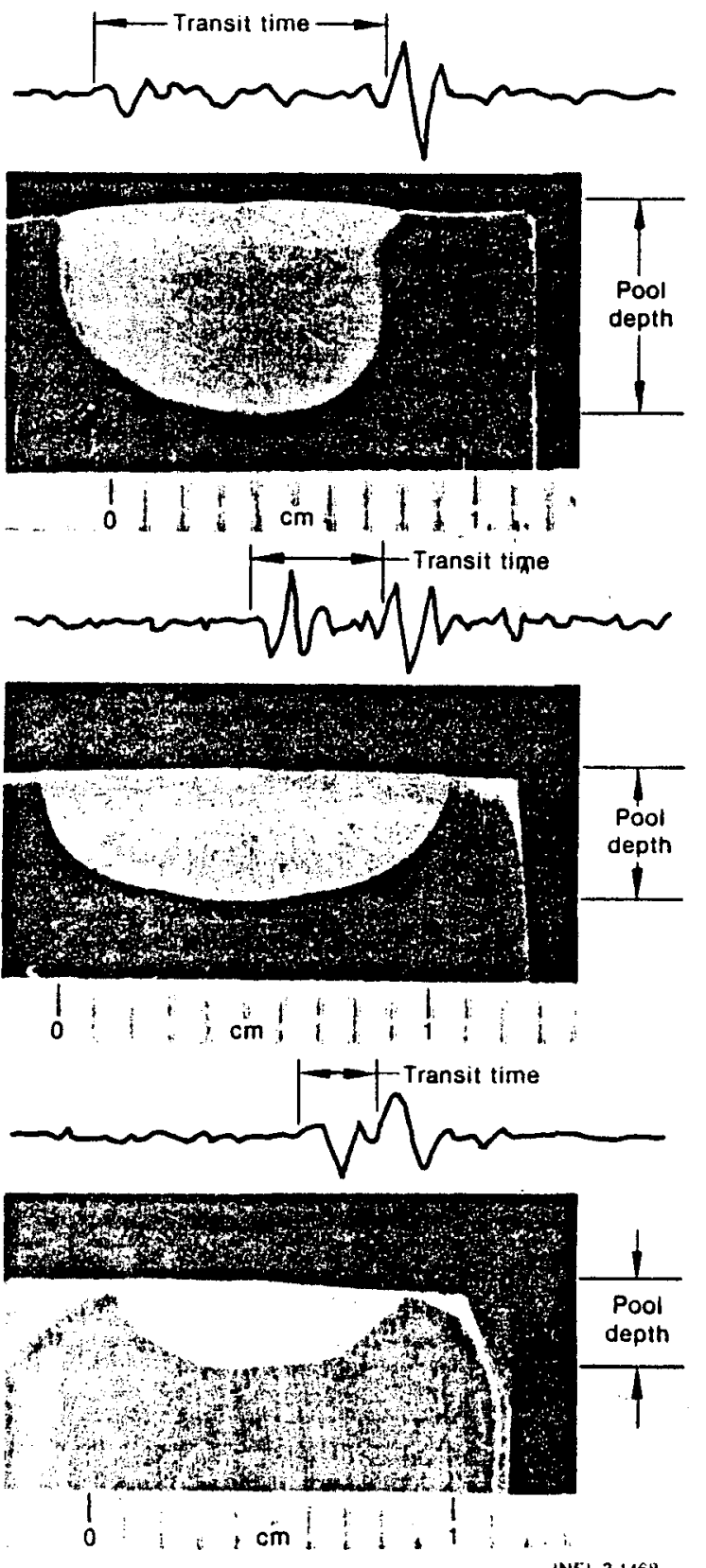

INEL 31468

Fig. 13 - Comparison of three weld pools of diflerent lephlis

techniques, or noncontact techniques such as electromagnetic acoustic transducers or

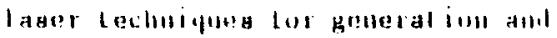
detection of ultrasonic waves. For welding geometries more complex than the stationary flat phate weld spots comsidered in hhis sludy, a more delailed knowledge of the effects of temperature grajients on wave

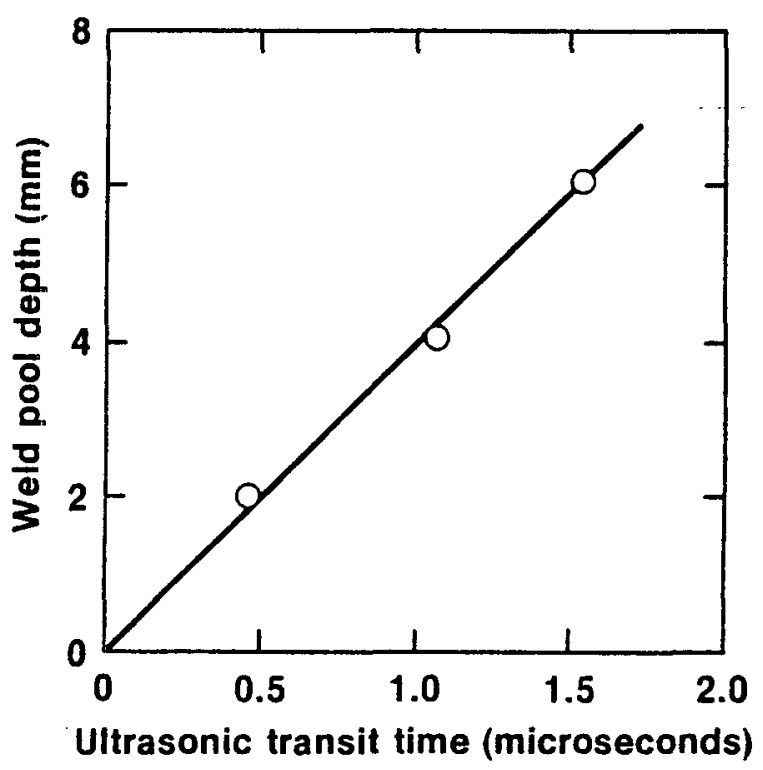

Fig. 14 - Correlation of weld-pool depth and cime difference between echoes

propagation will be necessary. Realistic weld configurations will also likely require tha use of ultrasonic shear waves entering from the cop surface of the structure being welded, and an investigation of weld zone detection by shear waves will be necessary. The fact that the ultrasonic signals reflected from liquid/solid interfaces of moiten weld pools are quite small will likely require the use of sophisticated signal processing techniques for detection and analysis of the data. Development of such techniques remains to be done. Finally, inuch work must be done to develop algorithms for specific process control applications, i.e., exactly how must the ultrasonic data be acquired, interpreted in terms of weld zone configuration, and converted to an optimum process control signal.

ACKNOWLEDGMENT

This wark was supported by the U.S. Department of Energy under DOE Contract No. DE-AC06-761DO1570.

MERIMLNGES

1. Vilkas, E. P., Welding Journal, 45 , $411-16(1)(20)$. 
2. Smartt, H. B. and J. F. Key, "An Investigation of factors Controlling Gl'A Weld Bead Geometry, "ASM Conference on Trends in welding Research in the United States, November 1981, New Orleans, I.A.

3. Parker, R. L. " "Physics in the Steel Industry," pp. 254-271, F. C. Schwerer (ed.), (1982) published by American Institute of Physics, New York, as AIP Conference Proceedings No. 84.

4. Lynnworth, L. C. and E. H. Carnevale, "Proceedings of the Fifth International Conference on Nondestructive Testing," Pp. 300-307, The Queen's Printer, Ottawa, Canada (1969).

5. Kurz, W. and B. Lux, Berg-und Hut tenmannische Monatshefte, $114 ;$ 123-130 (1969) (in German).

6. Kurz, W. and B. Lux, Translated from Archiv f. d. Eisenhut tenwesen, 39 , 521-530 ( 1968 ), Available in English from Henry Brutcher Translations, ASM, Metals Park, Ohio as HB No. 7528.

7. Kurz, W. and B. Lux, Zeits. Metallkunde, 57, 70-73 (1968), (in German).
8. Bailey, J. A. and A. Dula, Rev. Sci. Instruments, 38, 535-538 (1967).

9. Bailey, J. A. and J. R. Davila, Appl. Sci. Res., 25, 245-261 (1971).

10. Bailey, J. A. and J. R. Davila, Journal of the Institute of Metals, 97, 248-251 (1969).

11. Jeskey, G. V., L. C. Lynnworth, and K. A. Fowler, AFS International Cast Metals Journal, 2, 26-30 (1977).

12. Katz, J. M., "Ultrasonic Measurement and Control of Weld Penetration, "M.S. thesis, Massachusetts Institute of Technology, 1982.

13. R. Hof fmann, "STEALTH, A Language Explicit Finite-Difference Code for Solids, Structural and Thermodynamic Analysis," EPRI NP-260, August 1976.

14. "Metals Handbook," 9th Edition, Vol. 3, pp. 34-35, American Society of Metals, Metals Park, Ohio (1980).

15. "Marks' Standard Handbook for Mechanical Engineers," p. 5-5, Theodore Baumeister (ed.), McGraw-Hill, New York (1978). 